\title{
Integrating theories to predict clothing purchase on SNS
}

\begin{abstract}
Purpose - This paper aims to design and test a conceptual model integrating UGT, SIC, and TPB theories to identify the drivers that lead users to develop intentions to purchase clothing products through SNS.

Design/methodology/approach - Using an online questionnaire, data were collected from customers of clothing products who visit the SNS of their preferred clothing brands $(\mathrm{N}=$ 1,003). Empirical results, using partial least squares (PLS) regressions, were used to test the conceptual model.
\end{abstract}

Findings - The results supported the model and showed, as the main result, that purchase intention through the use of SNS is affected positively by intentions to use SNS and SNS use. SNS use is influenced by intentions to use SNS and by uses and gratifications (UGT). Intentions to use SNS are affected positively by UGT, attitude, and perceived behavioral control (PBC). Attitude is influenced positively by UGT, self-image congruity, PBC, and subjective norm $(\mathrm{SN})$.

Social implications - These findings reveal that the critical elements in achieving purchase intentions in users through SNS include obtaining their participation by managing the SNS according to users' self-image and offering useful gratifications.

Originality/value - This study integrates theories of SIC, UGT, and the TPB in a context of technology post-adoption to understand users' purchase intentions through SNS. By establishing this novel theoretical integration approach, this research furthers insight into purchase intentions through SNS.

Keywords - Social network site, self-image congruity, uses and gratifications, theory of planned behavior, purchase intentions

Paper type - Research paper 


\section{Introduction}

SNS pages are also becoming pivotal in influencing users' willingness to buy products or services (Poyry et al., 2013). Some of the most famous SNS, such as Facebook, Instagram and Twitter, have, respectively, 2.2 billion monthly active users, 813 million monthly active accounts, and 330 million monthly active users (Statista, 2018a). All of this large number of users could be influenced by the brands' communication strategies in SNS. In fact, $42.17 \%$ of consumers in the United States felt that SNS significantly influenced their decisions to purchase goods and services (Statista, 2018b), and in Spain, for example, 14\% of SNS users admit that they use them to buy products and services (IAB, 2016). However, contrary to what happens, little research has specifically analyzed the antecedents of purchase intentions through the brands' SNS. Research on SNS has been mostly based on the adoption and use of SNS as communication technologies (Al Debei et al., 2013; Baker and White, 2010; Wu, 2015).

In the context of SNS, UGT and the TPB have been previously used to explain participation and intentions to use these networks. Earlier research has verified the influence of UGT and TPB in explaining intentions to use SNS (Al-Debei et al., 2013; Baker and White, 2010; Chiang, 2013; Han et al., 2015). Additionally research on UGT has identified the substantial relations between the use intensity of substantial domains of SNS, such as contents, friend management, group coordination and gaming, and the perception of gratifications, (Leiner $e t$ al., 2018), the relationship between motives and behavioral outcomes of use on Instagram (Sheldon et al., 2017), the differences in the gratifications dimensions perceived by users depending on the type of social media use (Phua et al., 2017), or users' gratifications in sharing photos on Facebook (Malik et al., 2016). These studies, despite the importance of SNS as commercial platforms, only analyze entertainment, such as participation, and intensity and intentions of use, rather than the purchase intentions via these platforms. In particular, research on purchase intentions through SNS has not increased proportionally with the growth and usage 
of SNS. In fact, the research being performed on SNS purchase intentions, using the TPB and UGT approaches, is as yet quite limited (Hajli et al., 2017; Osatuyi and Qin, 2018).

According to self-image theories, people purchase products and services that are consistent with their own self-image (Sirgy et al., 2008). Thus, SIC facilitates consumers' development of a positive attitude toward products and brands (Ekinci and Riley, 2003). Since SIC may act as a psychological driver of the users' attitude toward the continuance intention to use SNS as an entertainment tool (Kang et al., 2013), it is expected that this variable may explain consumers' attitudes and intentions toward these commercial platforms. Nonetheless, to our knowledge, the literature that examines the role of SIC in relation to SNS clothing brand pages is scarce, and, even more, in theoretical models that integrate TPB and UGT theories.

Given these gaps in previous research, the SIC Theory, the UGT, and the TPB are integrated in this study to propose a conceptual model which aims to identify the drivers that influence users' intentions to purchase through clothing brands' SNS.

The purpose of this study is, therefore, to propose a conceptual framework and test it to identify the drivers that lead users toward purchase intentions through the SNS of clothing brands. More specifically, this research examines the simultaneous relationships between UGT, SIC, attitudes toward SNS, PBC, intentions to use SNS, and purchase intentions in SNS.

\section{Literature review and research model}

\subsection{Self-image congruity}

Research in marketing has investigated SIC grounded in the Self-Theory. This theory asserts that an individual's behavior is directly related to the improvement of their self-concept, which must be congruent with oneself (Kwak and Kang, 2009). Sirgy (1982) posits that brands satisfy consumers' needs according to their degree of congruence with the customer's actual or ideal self-concept. Additionally, previous literature on consumer behavior suggests that a consumer's 
self-image can be confirmed, expressed, and improved through the purchase of products (Sirgy, 1982).

The concept of self-image has been extended to self-image congruence, which is based on the idea that consumers' purchasing decisions are related to the image of the product. This means that there are coincidences between the image of the product and consumers' own image of themselves (Kressmann et al., 2006), which implies that customers who think their selfimage is congruent with the brand feel more social pressure through their reference groups (Shin et al., 2016). Likewise, self-image congruity is a predictor of an individual behavior (HajSalem et al., 2016) and the forming of favorable attitudes toward a product (Ibrahim and Najjar, 2008). Previous literature identified the positive on attitude, among e-reader users (Anton et al. (2013), and one attitudinal variable, namely, engagement (Islam et al., 2018). Consequently, it is assumed that consumers who perceive a clothing brand page on SNS to be compatible with their image will tend to develop favorable attitudes toward the clothing brand's SNS page. So, the following hypothesis is proposed:

$H_{1}$. SIC has a positive effect on a user's attitude toward the SNS.

To the best of our knowledge, the influence of SIC on SN has not been studied within the context of clothing brands' SNS pages. Nevertheless, it has been tested in other contexts. For example, the findings of Shin et al. (2016) confirmed that SIC has a positive influence on the $\mathrm{SN}$ in a study involving a local food brand. Therefore, it is likely that this relationship will be positive also in the context of this research. Thus, users with a higher level of SIC with the clothing brand's SNS page may be more likely to feel more social control. Therefore, the following hypothesis is expected:

$H_{2}$ SIC has a positive effect on a user's SN toward the SNS. 


\subsection{Uses \& Gratifications}

The UGT approach refers to the behavior of individuals in relation to the media, and it explains psychological and social antecedents and the subsequent attitudinal and behavioral effects of media consumption (Apaolaza et al., 2014), and it assumes that individuals seek gratifications in the consumption of traditional media (Katz et al., 1973). This theory has also been used to investigate other mass media technologies such as webpages (Luo et al., 2011), smartphone users (Ha et al., 2015), online games (Huang and Hsieh, 2011), and SNS (Al-Debei et al., 2013; Han et al., 2015). This research supports the potential explanatory ability of UGT to predict individual behaviors in SNS in order to encourage users to consume media, to interact, and to share content and information (Apaolaza et al., 2014).

SNS users access SNS through different devices, connecting to multiple networks and taking advantage of multiple social resources at any time. However, the different design and usability features of SNS, such as Facebook, Instagram or Twitter, may result in significant differences as regards the gratifications for using them (Phua et al., 2017). In fact, there is no consensus among researchers on measuring the construct, and it depends on the research context. This study focuses on the UGT variables that have been used repeatedly in previous research, such as information seeking, affection, leisure, and social presence (Luo et al., 2011; Xu et al., 2012).

The selection of media will depend on the SNS user's beliefs and expectations to meet specific needs (Choi et al., 2009), and the attitude of an individual toward an object is dependent on their beliefs (Fishbein and Ajzen, 1975). Previous literature has identified the influence of UGT on attitude among SNS users (Chiang, 2013; Curras-Perez et al., 2014; Ho and See-Too, 2018), the positive effect of UGT on intentions to use among users of Facebook (Cheung et al., 2011; Ifnedo, 2016), Twitter (Han et al., 2015), and among users of travelrelated social media (Hur et al., 2017), while other researchers find a positive effect of UGT on satisfaction and continuance intention among social commerce users of Facebook and 
Twitter (Osatuyi and Qin, 2018). Thus, if a user perceived similar gratifications in a clothing brand's SNS pages, it is expected that they will increase their attitude toward and intentions to use the clothing brand's SNS page. Hence, the following hypotheses are proposed:

$H_{3}$ : UGT have a positive effect on a user's attitude toward the SNS.

$H_{4}$ : UGT have a positive effect on a user's intention to use toward the SNS.

\subsection{The Theory of Planned Behavior (TPB)}

The TPB has its origins in the theory of reasoned action (TRA) (Fishbein and Ajzen, 1975), which proposes that an individual's behavior is affected by behavioral intentions, which are in turn affected by attitude and by SN. Fishbein and Ajzen (1975) define attitude and SN as the favorable or unfavorable evaluation of performing an act, and the function of beliefs about the reference groups and the motivations to act in accordance with the individual's referent groups, respectively.

An extension of this theory is TPB (Ajzen, 1991). TPB gathers the antecedents of the behavioral intentions of the TRA and adds PBC. Ajzen (1991) defines PBC as the intensity with which the individual perceives that they can control their behavior toward a certain action. TPB concludes that individuals' intention to behave in a certain way is influenced by attitude, PBC and SN, while behavior is influenced by intentions and PBC.

Past studies on SNS have indicated that SN, attitude, and PBC are significantly related to behavioral intentions (intentions to use) in entertainment contexts (Al Debei et al., 2013; Baker and White, 2010; Kim et al., 2016). They are also partially related, as in the case of the positive effect of SN and attitude on intentions to use SNS (Chiang, 2013), to the positive effect of attitude on intentions among users of social networking tourism sites (French et al., 2017), or the influence of SN on intentions to use SNS (Ku et al., 2013). Thus, based on the findings obtained in this previous literature, there is a positive effect on the relationship between SN and intention to use. Accordingly, this research proposes that higher levels of SN will lead to 
higher levels of intention to use clothing brands' SNS pages. This leads to the following hypothesis:

$H_{5 .}$ SN has a positive effect on the user's intention to use toward the SNS.

These previous studies supported the premise that when users have a positive attitude toward an SNS, they show more intentions to use it. Therefore, the following hypothesis is proposed:

$H_{6}$. The attitude toward a clothing brand's SNS page has a positive effect on the user's intention to use toward the SNS.

Regarding PBC, a user's perceived control may be related to relevant knowledge about functionality, uses, and control of the socialization system of the clothing brand's SNS page. Thus, SNS users' PBC regarding the clothing brand's SNS page exerts a positive influence on their intention to use. This leads to the following hypothesis:

$H_{7}$. PBC toward a clothing brand's SNS page has a positive effect on the user's intention to use it.

\subsection{Purchase intentions}

The TRA explains that intentions are the determinants of behavior (Fishbein and Ajzen, 1975), and so purchase intentions indicate the consumer's tendency to purchase a service or a product (Yoo et al., 2000), as well as being a combination of interest in the purchase and the possibility of purchase (Wu et al., 2015). Consumer behavior literature has used purchase intentions as a measure of loyalty in various sectors (Aksoy et al., 2013; Huang et al., 2015), while other authors have used them as a latent variable in structural models (Hsu and Lin, 2015). Furthermore, it is accepted that consumers who have no experience with a certain product or service may usually rely on word-of-mouth to acquire information (Bansal and Voyer, 2000), and SNS play an important role in electronic word-of-mouth (Luo and Zhong, 2015). Little research has been conducted to identify the influence of intentions to use SNS on purchase 
intentions via SNS. Previous authors have identified a positive direct relationship between participation in online communities and the intentions to use the services of a web community (Casaló et al., 2010). The relationship between the intentions to use SNS and the intentions to purchase products remains underexplored. In this respect, Poyry et al. (2013) found a direct positive relationship between browsing the Facebook page of a travel agency and the intention to purchase services. Since browsing implies intentions to use, SNS behavioral intentions are expected to determine users' willingness to purchase products from the brand's SNS. Accordingly, the following hypothesis is proposed:

$H_{8}$. Intentions to use SNS have a positive effect on the users' purchase intentions.

This study constructed a research model by using the SIC, UGT, and TPB theories as the theoretical basis, as has been explained previously. The research model is shown in Figure 1 and summarizes the hypotheses posited in this research:

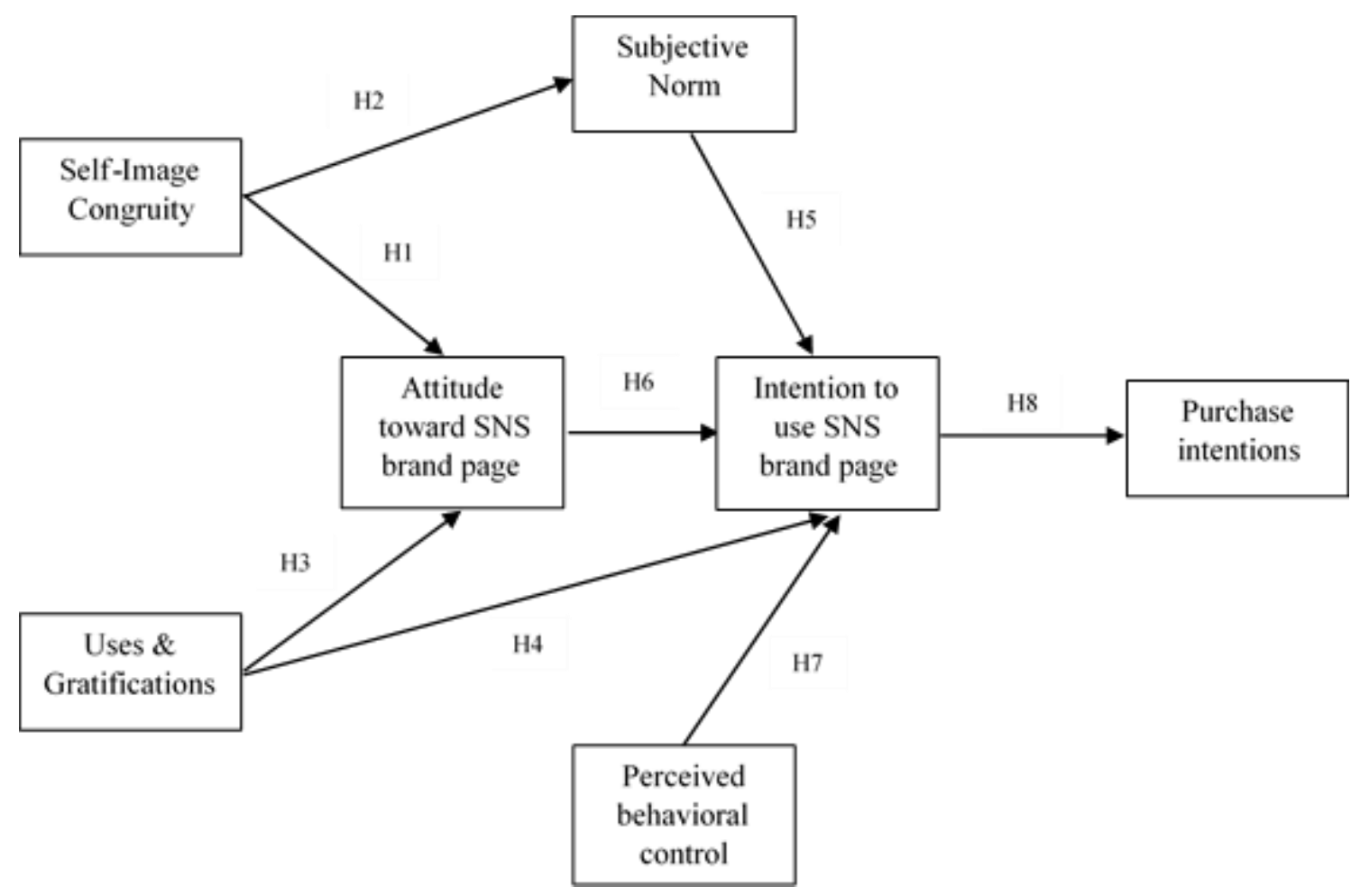

Figure 1. Research model 


\section{Methodology}

\subsection{Data collection}

This study focuses on customers of clothing products that visit the SNS of their preferred clothing brands. Data were collected by using a panel of consumers through an international independent online supplier of market research. The sample obtained with the panel was segmented according to different socio-demographic variables in order to obtain a representative sample of the universe of users of Spanish clothing brands' SNS (IAB, 2016). To gather the required data, an electronic questionnaire was designed. The period for the data collection was between the months of April and June 2016. The final sampling provided 1,003 valid questionnaires. Table I shows the profile of the sample.

Table I. Profile of the sample

\begin{tabular}{cccc}
\hline Variable & Frequency & Variable & Frequency \\
\hline Gender & & Age & \\
Male & $18.9 \%$ & $18-24$ & $27.1 \%$ \\
Female & $81.1 \%$ & $25-34$ & $40 \%$ \\
Level of education & & $35-44$ & $32.9 \%$ \\
& & Occupation & $54 \%$ \\
Without education & $0.5 \%$ & Employed & $6.1 \%$ \\
Basic studies & $11.3 \%$ & Self-employed & $23.6 \%$ \\
Higher studies & $40.9 \%$ & Student & $0.2 \%$ \\
University studies & $47.4 \%$ & Retired & $14.6 \%$ \\
& & Unemployed & $1.5 \%$ \\
SNS used & Others & $27.6 \%$ \\
Facebook & Average time on fashion website \\
Instagram & $63 \%$ & Less than 5 minutes & $38.3 \%$ \\
Others (Twitter, Pinterest, etc.) & $14 \%$ & $6-15$ minutes & $20.3 \%$ \\
& $23 \%$ & $16-29$ minutes & $13.8 \%$ \\
\hline
\end{tabular}

\subsection{Measurement}

To measure the different variables included in the study, 7-point multi-item Likert scales $(1=$ strongly disagree; 7 = strongly agree) were adapted from previous studies to fit the research context.

SIC was measured with four items: three items from the study by Kang et al. (2013), and one item from the research by Lee and Jeong (2014). The instrument of UGT consisted of four 
dimensions called Information Seeking (IS), Affection (AFF), Social Presence (SP), and Leisure (LEI). IS comprises three items from Park et al. (2009). Four items from Xu et al. (2012) make up the AFF scale. SP was measured with four items from Cheung et al. (2011), and LEI includes five items from Xu et al. (2012). UGT is modeled as a second-order formative measure with formative first-order dimensions and reflective indicators. In agreement with the nature of this variable, UGT is a multidimensional construct where each dimension has a specific content domain and may behave independently. This happens because these dimensions are not necessarily highly correlated and reflecting the same underlying construct.

The SN scale was formed by six items from Mäntymäki et al. (2014) and Chiang (2013). Similarly, PBC was composed of four items adapted from Al Debei et al. (2013) and Mäntymäki et al. (2014), while attitude was measured with three items from Al Debei et al. (2013) and one item from the study by Baker and White (2010). Finally, intention to use SNS was based on three items from Al Debei et al. (2013), while purchase intention was assessed with two indicators from Tsai and Huang (2007).

\subsection{Common method bias assessment}

Common method bias (CMB) refers to the variations in responses in self-reported data that are caused by the employed instrument rather than by the real constructs that these measures represent. Logically, concerns about CMB may arise when self-report measures obtained from the same sample are utilized. Since a single informant to measure the model's variables was employed, CMB was examined through different procedural and statistical methods (Podsakoff et al., 2003). First, respondent confidentiality and anonymity of the data was guaranteed. This may reduce the possibility of respondents responding artificially or dishonestly (Podsakoff $e t$ al., 2003). Second, the use of electronic questionnaires should decrease social desirability bias (Podsakoff et al., 2003). Third, exploratory factor analysis allowed us to assess the data factorial structure to detect potential CMB (Podsakoff et al., 2003). Exploratory factor analysis 
with SPSS revealed the existence of a number of different factors and that no single factor was accumulating the majority of the explained variance. The factor that accumulated the largest portion of variance had a value of $10.34 \%$. Therefore, common method bias does not seem to be a problem in this research. Finally, a full collinearity test based on variance inflation factors (VIFs) following Kock's (2015) procedure was implemented. The estimations showed that VIF values ranged from 1.138 to 2.063 , thus suggesting, again, that CMB is not a serious problem in this research.

\section{Analysis and results}

To test the hypotheses, Structural Equation Modelling with Partial Least Squares (SEM-PLS) was applied with the SMART-PLS 3.2 software application. SEM-PLS is a multivariate statistical analysis technique that is used to analyze the structural relationships between observed variables and latent constructs. SEM.PLS is a distribution-independent method that has fewer constraints and statistical assumptions than traditional covariance-based methods and that is primarily used for prediction in causal models. This methodology is suitable when the interest of the study is focused on prediction and theory development rather than on theory confirmation (Reinartz et al., 2009). PLS is especially recommended in situations where the researchers aim to complete confirmed models with new variables and structural paths, when the phenomenon under research is new or changing, or when different theories are integrated to define the model (Roldan and Sánchez-Franco, 2012). To our knowledge, no studies have combined SIC theories, the TPB, and theories related to UGT to explain customers' purchase behaviors in SNS. Moreover, PLS offers advantages over traditional structural modeling for estimating models where formative variables, like UGT, are present (Hair et al., 2011). In view of these conditions, PLS seems to be particularly suitable for use in this study.

PLS-SEM analysis requires researchers to, firstly, evaluate the measurement model before examining the significance of the structural paths. If the measurement model accomplishes 
certain required criteria, researchers should then evaluate the structural model in a second stage. These analysis are shown in the following sections.

\subsection{Analysis of the measurement model}

The first step of the analysis using the PLS methodology requires the estimation of the measurement model. This analysis will reveal the suitability of the measures by examining their reliability and validity. As previously described, the UGT construct is conceived as a formative second-order factor composed of four first-order reflective constructs. To estimate second-order models with PLS, a two-stage approach was implemented in accordance with the procedure described by Wetzels et al. (2009). In the first stage, a model with the first-order constructs was estimated. This model included the first-order dimensions of UGT as separate independent constructs. This estimation provided us with the latent variable scores to be used in the estimation of the second-order factor model in stage two.

In the stage-one estimation, reliability and validity of the first-order constructs were assessed. According to these results, all the items met or were very close to the typical threshold of 0.7 required to guarantee individual item reliability (Carmines and Zeller, 1979). Items LEI3 $(\lambda=0.352)$ and ISEE4 $(\lambda=0.570)$ were removed because of their low individual reliability. Item SN3 $(\lambda=0.678)$ was slightly below the critical threshold but it was maintained in the model to preserve content validity and because the composite reliability of the constructs showed satisfactory levels. Indeed, all the constructs were internally consistent, since the composite reliability $(\mathrm{CR})$ indexes were above 0.7 . As regards the validity analysis, the constructs met the convergent validity criteria, since the average variance extracted (AVE) yielded values above $50 \%$. Moreover, the existence of discriminant validity was verified by examining the Heterotrait-Monotrait ratios between the constructs and by comparing the square root of the AVE values with the correlations of the latent variables. Discriminant validity was supported, 
since the HTMT ratios were below the 0.90 threshold, and the square root of the AVE values was larger than the correlations of the constructs (Henseler et al., 2015).

The results of the model estimation in stage two are shown in Table II. For the reflective constructs, indicators presented individual reliability and the constructs met composite reliability and convergent validity criteria. Discriminant validity was also confirmed by using the HTMT criteria (Table III) and the Fornell and Larcker (1981) criterion. For the formative dimensions, validity was determined by the significance and strength of the weight from every formative indicator (first-order construct) in the formative latent construct (second-order construct) (MacKenzie et al., 2005). The weights of the four formative dimensions of UGT suggested that each dimension was an important indicator of the second-order latent variable with weights ranging from 0.175 to 0.486 .

Table II. Results of the final measurement model

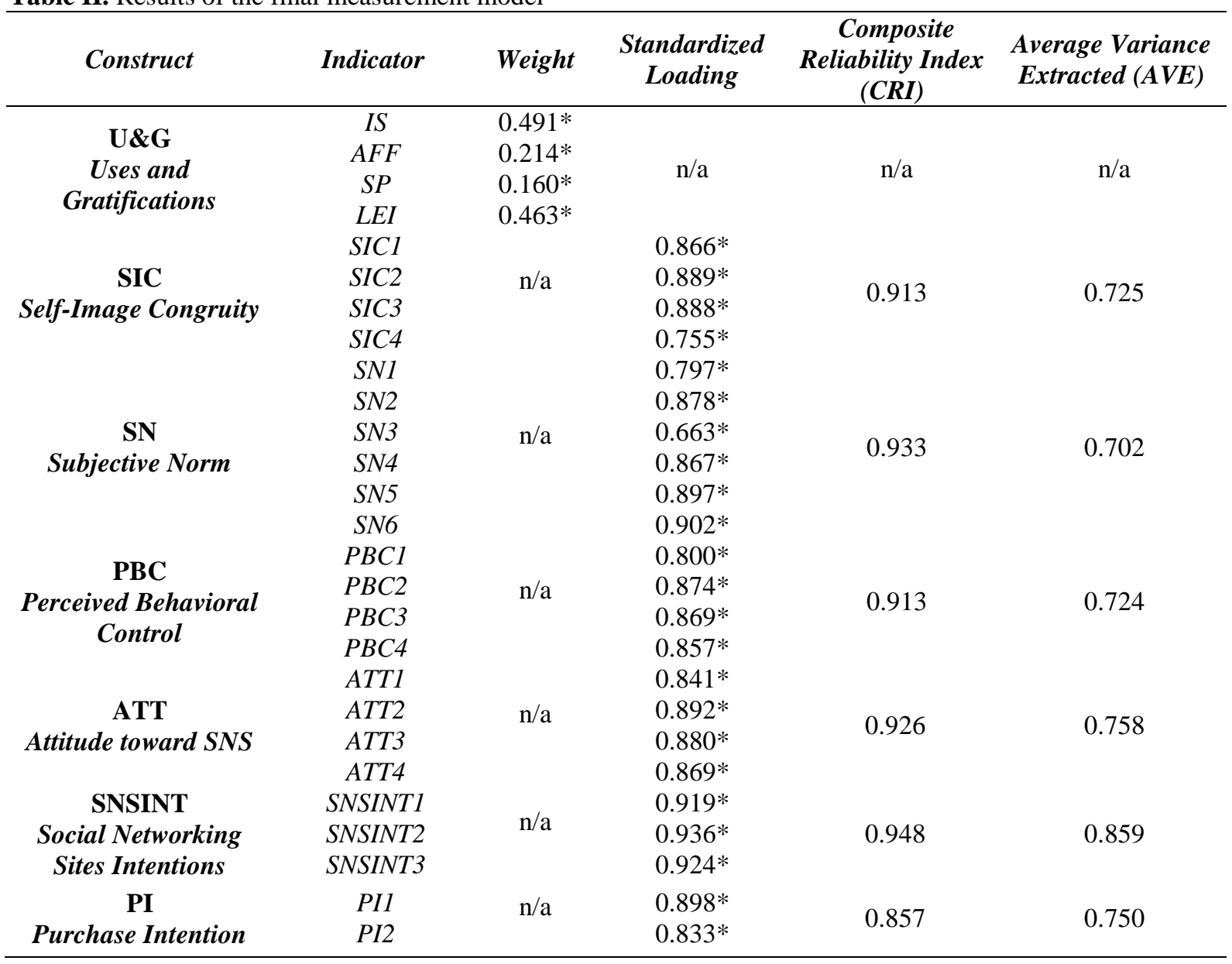


Table III. Discriminant validity of the final measurement model

\begin{tabular}{cccccccc}
\hline Construct & $\mathbf{1}$ & $\mathbf{2}$ & $\mathbf{3}$ & $\mathbf{4}$ & $\mathbf{5}$ & $\mathbf{6}$ & $\mathbf{7}$ \\
\hline 1. U\&G & $\mathrm{n} / \mathrm{a}$ & $\mathrm{n} / \mathrm{a}$ & $\mathrm{n} / \mathrm{a}$ & $\mathrm{n} / \mathrm{a}$ & $\mathrm{n} / \mathrm{a}$ & $\mathrm{n} / \mathrm{a}$ & $\mathrm{n} / \mathrm{a}$ \\
2. SIC & $\mathrm{n} / \mathrm{a}$ & $\mathbf{0 . 8 5 2}$ & 0.662 & 0.106 & 0.499 & 0.348 & 0.753 \\
3. SN & $\mathrm{n} / \mathrm{a}$ & 0.594 & $\mathbf{0 . 8 3 8}$ & 0.144 & 0.652 & 0.450 & 0.612 \\
4. PBC & $\mathrm{n} / \mathrm{a}$ & -0.003 & 0.134 & $\mathbf{0 . 8 5 1}$ & 0.410 & 0.518 & 0.115 \\
5. ATT & $\mathrm{n} / \mathrm{a}$ & 0.446 & 0.590 & 0.372 & $\mathbf{0 . 8 7 1}$ & 0.643 & 0.465 \\
6. SNSINT & $\mathrm{n} / \mathrm{a}$ & 0.322 & 0.413 & 0.471 & 0.583 & $\mathbf{0 . 9 2 7}$ & 0.412 \\
7. PI & $\mathrm{n} / \mathrm{a}$ & 0.579 & 0.483 & -0.076 & 0.364 & 0.327 & $\mathbf{0 . 8 6 6}$ \\
\hline
\end{tabular}

\subsection{Analysis of the structural model}

Once the measurement model is confirmed to be acceptable, the next step in PLS-SEM involves assessing the structural model in order to test the statistical significance of the structural paths. A bootstrapping procedure with 5,000 subsamples was employed for this purpose (Hair et al., 2011). Bootstrapping is a non-parametric re-sampling technique that provides standard errors and t-statistics of the parameters (Efron and Tibshirani, 1993). The results of the bootstrapping analysis revealed that factorial loadings and weights were statistically significant at $1 \%$. In this stage, the model's explanatory power should be examined by assessing the $\mathrm{R}^{2}$ of the endogenous constructs. The model explained $36.5 \%$ of the ATT construct's variance, $52.4 \%$ of SNSINT, $35 \%$ of SN, and $10.7 \%$ of PI. Also, the predictive relevance of the model was also examined through a Stone-Geisser test, which revealed that the dependent variables of the model could indeed be predicted by the independent constructs.

Once the explanatory and predictive power of the model is guaranteed, the final step in PLSSEM is to assess the statistical significance and relevance of the structural path coefficients. According to the results of the structural model (Table IV, and Figure 2), SIC has a positive and significant effect on customers' attitude toward SNS $(\beta=0.179 ; \mathrm{t}=5.868)$, thus confirming Hypothesis 1 , and on $\mathrm{SN}(\beta=0.592 ; \mathrm{t}=24.584)$, which means Hypothesis 2 can be accepted. Estimations also revealed that UGT significantly explains customers' attitudes $(\beta=0.490$; $\mathrm{t}=15.192)$ and intentions to use SNS $(\beta=0.414 ; \mathrm{t}=11.593)$. Therefore, Hypotheses 3 and 4 are accepted. $\mathrm{SN}$ does not have a significant impact upon intentions to use $\mathrm{SNS}(\beta=0.015 ; \mathrm{t}=0.506)$, 
while the customer's attitude toward SNS has a positive and significant influence on intentions to use SNS $(\beta=0.251 ; \mathrm{t}=6.169)$, thereby rejecting Hypothesis 5 and confirming Hypothesis 6. Focusing on the influence of $\mathrm{PBC}$, estimations indicated that, as expected, this variable positively and significantly affected customers' intentions to use the SNS ( $\beta=0.219 ; \mathrm{t}=7.506)$ of their favorite clothing brands, thus confirming Hypothesis 7. Finally, as hypothesized, SNS intentions significantly predicted customers' willingness to purchase products of their favorite brand through SNS $(\beta=0.327 ; \mathrm{t}=11.654)$. Coherently, these findings lead us to accept Hypothesis 8.

Table IV. Results of the structural model

\begin{tabular}{|c|c|c|}
\hline Hypothesis & $\boldsymbol{\beta}$ & t-value \\
\hline H1) Self-Image Congruity $\rightarrow$ Attitude & 0.179 & 5.868 \\
\hline H2) Self-Image Congruity $\rightarrow$ Subjective Norm & 0.592 & 24.584 \\
\hline H3) Uses \& Gratifications $\rightarrow$ Attitude & 0.490 & 15.192 \\
\hline H4) Uses \& Gratifications $\rightarrow$ SNS Intentions & 0.414 & 11.593 \\
\hline H5) Subjective Norm $\rightarrow$ SNS Intentions & 0.015 & $0.506^{*}$ \\
\hline H6) Attitude $\rightarrow$ SNS Intentions & 0.251 & 6.169 \\
\hline H7) Perceived Behavioral Control $\rightarrow$ SNS Intentions & 0.219 & 7.506 \\
\hline H8) SNS Intentions $\rightarrow$ Purchase Intentions & 0.327 & 11.654 \\
\hline \multicolumn{3}{|c|}{$*_{\text {ns }}$ (not significant), $\mathbf{R}^{\mathbf{2}}$ and Predictive Relevance $\left(\mathbf{Q}^{2}\right)$} \\
\hline \multicolumn{3}{|c|}{$\mathrm{R}^{2}-\mathrm{ATT}=0.365 ; \mathrm{R}^{2}-\mathrm{SNSINT}=0.524 ; \mathrm{R}^{2}-\mathrm{SN}=0.350 ; \mathrm{R}^{2}-\mathrm{PI}=0.107$} \\
\hline \multicolumn{3}{|c|}{$\mathrm{Q}^{2}-\mathrm{ATT}=0.261 ; \mathrm{Q}^{2}-\mathrm{SNSINT}=0.425 ; \mathrm{Q}^{2}-\mathrm{SN}=0.230 ; \mathrm{Q}^{2}-\mathrm{PI}=0.074$} \\
\hline
\end{tabular}




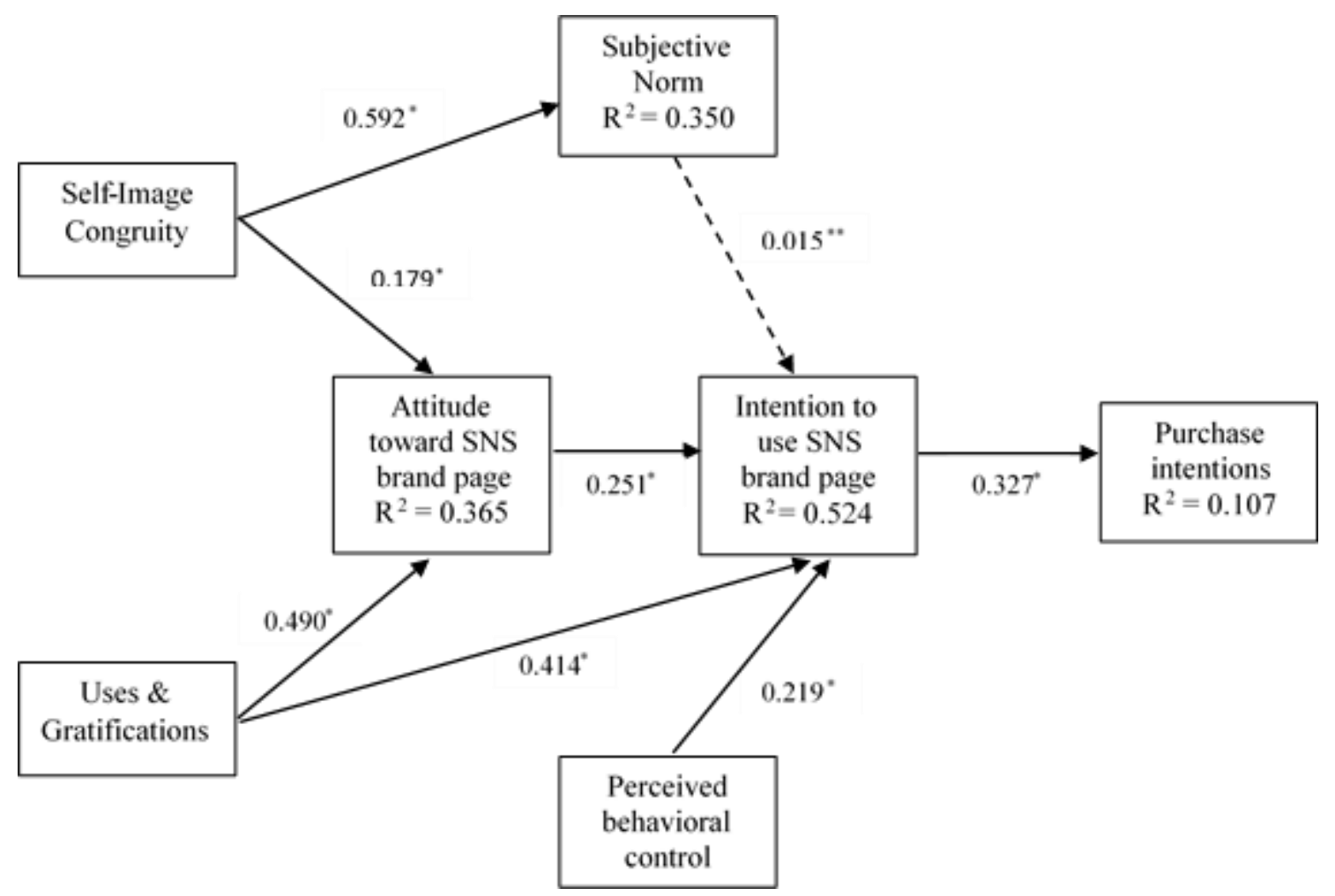

Figure 2. Structural Model Path Coefficients

Notes: $* p<0.001 ; * *$ Not significant

\section{Discussion}

The main objective of this study was to design and test a conceptual model integrating UGT, SIC, and TPB theories to identify the drivers that lead users to develop intentions to purchase through SNS, mainly Facebook and Instagram. No prior research has used these theoretical frameworks to investigate the intentions to purchase products through SNS. The results largely support the theoretical model, since seven of the eight proposed hypotheses are accepted and provide further evidence of the applicability and suitability of UGT, SIC, and TPB to understand the phenomenon of intention to purchase clothing through social networks.

The findings obtained after applying SIC theory revealed a positive influence of SIC on attitude and on SN. The former is in line with previous research in other contexts (Anton et al., 2013; Ibrahim and Najjar, 2008), which means that a positive attitude is generated toward the clothing brands' SNS pages when they are able to reflect the image of their users. This positive 
relationship reflects users' perceptions of themselves as individuals who think that the use of SNS is positive, good, appropriate, and pleasant as a means to maintain their self-image. Regarding the positive relationship between SIC and SN, which has remained underexplored to date in the SNS context, the results show that users feel that a higher impact of SIC on SN leads to a greater sense of social control. This finding is congruent with Shin et al. (2016), who found that the SIC of purchasers of local food displayed a positive effect on SN. Nonetheless, contrary to our expectations and previous literature (Al-Debei et al., 2013; Ku et al., 2013), SN does not influence intentions to use SNS. This finding suggests that this relationship is positive when interactions with others are an essential driver to use SNS (Baker and White, 2010; Curras-Perez et al., 2014; Kim et al., 2016), although when the purpose of users is more utilitarian, such as purchasing products, the reference groups' opinion is not significant.

The results of the application of UGT determined the major role of UGT in influencing attitude (Curras-Perez, 2014), as well as intentions to use SNS (Li et al., 2015). These results suggest that users of clothing brands' pages on SNS need to seek out information about the novelties as well as to share information, interact, and socialize with each other, in addition to having some entertainment prior to expressing an attitude (Ho and See-Too, 2018). Hence, users of clothing brands' SNS pages need more motivational UGT dimensions than those who use social networks with friends, as shown in the studies by Curras-Perez et al. (2014) and Chiang (2013), who only identified sociability and entertainment, the first, and playfulness, the second, as dimensions of UGT that exerted a positive influence on attitude. The same thing happens with the positive relationship between UGT and intentions to use SNS if our findings are compared with previous literature. Li et al. (2015) identified the positive effect of UGT on intentions to use among users of online games, but their dimensions of UGT were hedonic, utilitarian, and social gratifications. In sum, the results of UGT in this research indicate that clothing brands' SNS pages are largely considered pleasure and interconnectivity oriented tools 
through which information, leisure and connections with other users interested in the brand can be obtained.

Finally, the findings of the application of TPB highlight the main role of attitude, PBC, and intentions to use SNS in the model. These findings revealed that the degree to which individuals perceive that they have control over their SNS use significantly predicts SNS intention, which confirms previous literature on SNS (Dermentzi et al., 2016). Furthermore, intentions to use SNS exert a strong influence on purchase intentions. This finding reflects those of Pöyry et al. (2013) by demonstrating that browsing on the SNS of clothing brands leads to purchase intentions. A possible explanation could be that SNS offer users the possibility to see novelties, clothing collections, and promotional offers, as if they were in a physical store. In fact, this finding would be related to the results of Duffet's study (2015), in which he found that the advertising that companies posted on Facebook favorably conditions attitudes toward the purchase of the products.

\section{Conclusion}

This study integrates theories of SIC, UGT, and the TPB in a context of technology postadoption to understand users' intentions to purchase through SNS. Thus, this study examines a model incorporating SIC, UGT, SN, attitude, PBC, SNS intentions, and purchase intentions among users of clothing brands' SNS pages. The results suggest that the model is partially tested and it should be noted that seven of the eight hypotheses were supported.

This research makes several contributions to the previous literature. First, this is one of the first studies to empirically test the antecedents to purchase clothing products through clothing brand's SNS pages. Second, it also makes some theoretical contributions to existing studies of intention to use SNS by integrating the theories of SIC and UGT, and contextualizing it within the framework of clothing brand's SNS pages. Third, four drivers, namely attitude, SIC, UGT, and PBC, were identified as antecedents of intention to use. Fourth, UGT was identified as a 
key determinant of attitude and intentions to use clothing brands' SNS pages. Fifth, the influence of SIC creates pressure by forming SN. However, for these users, the influence of the reference groups on the use of the clothing brands' SNS pages is not significant.

From a practical perspective, managers can benefit from the findings of this research in designing their strategies to achieve short- and medium-term objectives, mainly on their Facebook and Instagram pages. This implies that clothing brands' SNS managers should focus on developing strategies to improve UGT, particularly in two of its dimensions: information seeking and leisure. Giving information about new products and new trends, as well as informing about brand events, and applying entertaining techniques, have been shown to be important influences on intentions to use SNS, which is the direct antecedent of purchase intentions. Furthermore, carrying out activities that promote contact between users, such as features that provide users with the means to gather information about the beliefs and values held by other users, would increase sociability among users and would further improve the perceived gratifications. Marketers should consider matching their SNS's image to users' SIC. To do so, managers should identify the ideal SIC of the users and develop marketing strategies, using celebrities, so that the users could identify with them. Another factor to improve is the users' attitude toward clothing brands' SNS pages. Competitions, raffles, promotions, and special discounts on clothing products could help the user to have a more positive attitude toward the clothing brand's SNS page.

The investigation has some limitations. First, the disproportion between men and women in the sample is due to the fact that women in Spain consume clothing brands' SNS pages far more than men. As a result, in other countries the situation might perhaps be more balanced and gender-moderating effects could be explored. Second, the low results of the variance $\left(\mathrm{R}^{2}\right)$ in purchase intentions show that both variables are also explained by other factors. Thus future research could consider incorporating other variables that positively and directly influence purchase intentions. Third, the research model is still evolving, given the emerging nature of 
purchasing through SNS. As more is learned about the factors involved in the technological process of buying, it is conceivable that more salient constructs may be identified and new relationships developed in future studies. Finally, another limitation of the study could be the fact that we do not separate continuous users from first-time users. First-time users might feel a different intensity of uses and gratifications to that felt by continuous users. Finally, from a methodological standpoint, more objective measures to capture customers' real purchasing patterns would reinforce this study's findings.

\section{References}

Al-Debei, M.M., Al-Lozi, E. and Papazafeiropoulou, A. (2013), "Why people keep back to Facebook: explaining and predicting continuance participation from an extended theory of planned behavior perspective”, Decision Support Systems, Vol. 55 No. 1, pp. 43-54.

Ajzen, I. (1991), "The theory of planned behavior", Organizational Behavior and Human Decision Processes, Vol. 50 No. 2, 179-211.

Aksoy, L., Buoye, A., Aksoy, P., Larivière, B. and Keiningham, T.L. (2013), “A cross-national investigation of the satisfaction and loyalty linkage for mobile telecommunications services across eight countries", Journal of Interactive Marketing, Vol. 27 No. 1, pp. 74-82.

Anton, C., Camarero, C., and Rodríguez, J. (2013), "Usefulness, and self-image congruence: the adoption of e-book readers", Psychology \& Marketing, Vol. 30 No. 4, pp. 372-384.

Apaolaza, V., He, J. and Hartmann, P. (2014), "The effect of gratifications derived from use of the social networking site Qzone on Chinese adolescents' positive mood", Computers in Human Behavior, Vol. 41, pp. 203-211.

Baker, R.K. and White, K.M. (2010), "Predicting adolescents' use of social networking sites from an extended theory of planned behaviour perspective", Computers in Human Behavior, Vol. 26 No. 6, pp. 1591-1597.

Bansal, H. S. and Voyer, P.A. (2000), "Word-of-mouth processes within a services purchase decision context", Journal of Service Research, Vol. 3 No. 2, pp. 166-177.

Carmines, E.G. and Zeller, R.A. (1979), Reliability and validity assessment, Sage, Newbury Park, CA.

Casaló, L. V., Flavián, C. and Guinalíu, M. (2010/2011), “Antecedents and consequences of consumer participation in on-line communities: The case of the travel sector", International Journal of Electronic Commerce, Vol. 15 No. 2, pp. 137-167.

Cheung, C.M.K., Chiu, P-Y. and Lee, M.K.O. (2011), "Online social networks: Why do students use facebook?", Computers in Human Behavior, Vol. 27, No. 4, pp. 1337-1343.

Chiang, H-S. (2013), "Continuous usage of social networking sites", Online Information Review, Vol. 37 No. 6, pp. 851-871.

Choi, Y.K., Kim, J. and McMillan, S.J. (2009), "Motivators for the intention to use mobile TV. A comparison of South Korean males and females", International Journal of Advertising, Vol. 28 No 1, pp. 147-167. 
Curras-Perez, R., Ruiz-Mafe, C. and Sanz-Blas, S. (2014), "Determinants of user behaviour and recommendation in social networks. An integrative approach from the uses and gratifications perspective", Industrial Management and Data Systems, Vol. 114 No. 9, pp. 1477-1498.

Dermentzi, E., Papagiannidis, S. Toro, C.O. and Yannopoulou, N. (2016), "Academic engagement: differences between intention to adopt social networking sites and other online technologies", Computers in Human Behavior, Vol. 61, pp. 321-332.

Duffet, R.G. (2015), "Facebook advertising's influence on intention-to-purchase and purchase amongst Millennials", Internet Research, Vol. 25 No. 4, pp. 498-526.

Efron, B. and Tibshirani, R.J. (1993), An introduction to the bootstrap, Chapman \& Hall, New York, NY.

Ekinci, Y. and Riley, M. (2003), "An investigation of self-concept: actual and ideal selfcongruence compared in the context of service evaluation", Journal of Retailing and Consumer Services, Vol. 10 No. 4, pp. 201-214.

Escobar-Rodríguez, T. and Carvajal-Trujillo, E. (2014) "Online purchasing tickets for low cost carriers: an application of the unified theory of acceptance and use of technology (UTAUT) model", Tourism Management, Vol. 43, pp. 70-88.

Fishbein, M. and Ajzen, I. (1975), Belief, attitude, intention, and behavior: an introduction to theory and research, Addison-Wesley, Reading, MA.

Fornell, C. and Larcker, D.F. (1981), "Evaluating structural equations models with unobservable variables and measurement error", Journal of Marketing Research, Vol. 18 No. 1, pp. 3950.

French, A.M., Luo, X. and Bose, R. (2017), "Toward a holistic understanding of continued use of social networking tourism: A mixed-methods approach", Information \& Management, Vol. 54 No 6, pp. 802-813.

Ha, W.Y., Kim, J., Libaque-Saenz, C.F., Chang, Y. and Park, M-C. (2015), "Use and gratifications of mobile SNSs: Facebook and KakaoTalk in Korea", Telematics and Informatics, Vol. 32 No 3, pp. 425-438.

Hair, J.F., Ringle, C.M. and M. Sarstedt, M. (2011), "PLS-SEM: Indeed a silver bullet", Journal of Marketing Theory and Practice, Vol. 19 No. 2, pp. 139-152.

Hajli, N., Sims, J., Zadeh, A.H. and Richard, M-O. (2017), "A social commerce investigation of the role of trust in a social networking site on purchase intentions", Journal of Business Research, Vol. 71, pp. 133-141.

Haj-Salem, N., Chebat, J.C., Michon, R. and Oliveira, S. (2016) "Why male and female shoppers do not see mall loyalty through the same lens? The mediating role of selfcongruity", Journal of Business Research, Vol. 69 No 3, pp. 1219-1227.

Han, S., Min, J. and Lee, H. (2015) "Antecedents of social presence and gratification of social connection needs in SNS: A study of Twitter users and their mobile and non-mobile usage", International Journal of Information Management, Vol. 35, pp. 459-471.

Henseler, J., Ringle, C.M. and Sarstedt, M. (2015), "A new criterion for assessing discriminant validity in variance-based structural equation modeling", Journal of the Academy of Marketing Science, Vol. 43 No. 1, pp. 115-135.

Ho, K.K.W. and See-Too, E.W.K. (2018), "The impact of the uses and gratifications of tourist attraction fan page", Internet Research, Vol. 28 No. 3, 1066-2243.

Huang, L-Y. and Hsieh, Y-J. (2011), "Predicting online game loyalty based on need gratification and experiential motives", Internet Research, Vol. 21 No 5, pp. 581-598.

Huang, S., Weiler, B. and G. Assaker, G. (2015) "Effects of interpretative guiding outcomes on tourist satisfaction and behavioral intention”, Journal of Travel Research, Vol. 54 No. 3 , pp. 344-358. 
Hsu, C-L. and Lin, J.C-C. (2015) "What drives purchase intention for paid mobile apps? - An expectation confirmation model with perceived value", Electronic Commerce Research and Applications, Vol. 14 No. 1, pp. 46-57.

Hur, K., Kim, T.T., Karatepe, O.M. and Lee, G. (2017), "An exploration of the factors influencing social media continuance usage and information sharing intentions among Korean travelers", Tourism Management, Vol. 63, pp. 170-178.

Ibrahim, H. and F. Najjar, F. (2008) "Assessing the effects of self-congruity, attitudes and customer satisfaction on customer behavioural intentions in retail environment", Marketing Intelligence \& Planning, Vol. 26 No. 2, pp. 207-227.

Ifnedo, P. (2016), "Applying uses and gratifications theory and social influence processes to understand students' pervasive adoption of social networking sites: perspectives from the Americas", International Journal of Information Management, Vol. 36 No. 2, pp. 192-206.

Interactive Advertising Bureau (IAB) (2016), "Estudio anual de las redes sociales [Annual report of social networking sites]," available at: http://www.iabspain.net/wpcontent/uploads/downloads/2016/04/IAB_EstudioRedesSociales_2016_VCorta.pdf, (accessed 9 December 2016).

Islam, J.U., Rahman, Z. and Hollebeek, L.D. (2018), "Consumer engagement in online brand communities: a solicitation of congruity theory ", Internet Research, Vol. 28 No 1, pp. 2345.

Kang, Y.S., Min, J., Kim, J. and Lee, H. (2013), "Roles of alternative and self-oriented perspectives in the context of the continued use of social network sites", International Journal of Information Management, Vol. 33, pp. 496-511.

Katz, E., Blumler, J.G. and Gurevitch, M. (1973), "Uses and gratifications research", Public Opinion Quarterly, Vol. 37 No. 4, pp. 509-523, 1973.

Kim, E., Lee, J-A., Sung, Y.M. and Choi, S.M. (2016), "Predicting selfie-posting on social networking sites: an extension of theory of planned behavior", Computers in Human Behavior, Vol. 62, pp. 116-123.

Kock, N. (2015), "Common method bias in PLS-SEM: a full collinearity assessment approach", International Journal of e-Collaboration, Vol. 11 No. 4, pp. 1-10.

Kressmann, F., Sirgy, M.J., Herrmann, A., Huber, F., Huber, S. and Lee, D-J. (2006), "Direct and indirect effects of self-image congruence on brand loyalty", Journal of Business Research, Vol. 59 No. 9, pp. 955-964.

$\mathrm{Ku}, \mathrm{Y}-\mathrm{C} ., \mathrm{Chen}, \mathrm{R}$. and Zhang, H. (2013),"Why do users continue using social networking sites? An exploratory study of members in the United States and Taiwan", Information \& Management, Vol. 50 No 7, pp. 571-581.

Kwak, D.H. and Kang, J-H. (2009), "Symbolic purchase in sport: the roles of self-image congruence and perceived quality", Management Decision, Vol. 47 No.1, pp. 85-99.

Lee, S. and Jeong, M. (2014), "Enhancing online brand experiences: an application of congruity theory", International Journal of Hospitality Management, Vol. 40 No. 1, pp. 49-58, 2014.

Leiner, D.J., Kobilke, L., Rueß, C. and Brosius, H-B. (2018), "Functional domains of social media platforms: Structuring the uses of Facebook to better understand its gratifications", Computers in Human Behavior, Vol. 83, pp. 194-203.

Li, H., Liu, Y., Xu, X., Heikkilä, J. and Van der Heijden, H. (2015), "Modeling hedonic is continuance through the uses and gratifications theory: an empirical study in online games", Computers in Human Behavior, Vol. 48, pp. 261-272.

Luo, M.M., Chea, S. and Chen, J-S. (2011), "Web-based information service adoption: a comparison of the motivational model and the uses and gratifications theory," Decision Support Systems, Vol. 51 No. 1, pp. 21-30.

Luo, Q. and Zhong, D. (2015), "Using social network analysis to explain communication characteristics of travel-related electronic word-of-mouth on social network sites", Tourism Management, Vol. 46, pp. 274-282. 
MacKenzie, S.B., Podsakoff, P.M. and Jarvis, C.B. (2005) "The problem of measurement model misspecification in behavioral and organizational research and some recommended solutions," Journal of Applied Psychology, Vol. 90 No. 4, pp. 710-730.

Malik, A., Dhir, A. and Nieminen, M. (2018), "Uses and Gratifications of digital photo sharing on Facebook", Telematics and Informatics, Vol. 33 No 4, pp. 129-138.

Mäntymäki, M., Merikivi, J. Verhagen, T., Feldberg, F. and Rajala, R. (2014), "Does a contextualized theory of planned behavior explain why teenagers stay in virtual worlds?", International Journal of Information Management, Vol. 34 No. 5, pp. 567-576.

Osatuyi, B. and Qin, H. (2018), "How vital is the role of affect on post-adoption behaviors? An examination of social commerce users", International Journal of Information and Management, Vol. 40, pp. 175-185.

Park, N., Kee, K.F. and S. Valenzuela, S. (2009), "Being immersed in social networking environment: Facebook groups, uses and gratifications, and social outcomes", Cyberpsychology and Behavior, Vol.12 No. 6, pp. 729-733.

Phua, J., Jin, S.V. and Kim, J. (2017), "Gratifications of using Facebook, Twitter, Instagram, or Snapchat to follow brands: The moderating effect of social comparison, trust, tie strength, and network homophily on brand identification, brand engagement, brand commitment, and membership intention", Telematics and Informatics, Vol. 34 No 1, pp. 412-424.

Phua, J, Jin, S.V. and Kim, J. (2017) "Uses and gratifications of social networking sites for bridging and bonding social capital: A comparison of Facebook, Twitter, Instagram, and Snapchat", Computers in Human Behavior, Vol. 72, pp. 115-122.

Podsakoff, P.M., MacKenzie, S.B., Lee, J.Y. and Podsakoff, N.P. (2003), "Common method biases in behavioral research: a critical review of the literature and recommended remedies", Journal of Applied Psychology, Vol. 88 No. 5, pp. 879-903.

Pöyry, E., Parvinen, P. and Malmivaara, T. (2013), "Can get from liking to buying? Behavioral differences in hedonic and utilitarian Facebook usage", Electronic Commerce Research and Applications, Vol. 12 No. 4, pp. 224-235.

Reinartz, W., Haenlein, M. and Henseler, J. (2009), “An empirical comparison of the efficacy of covariance-based and variance-based SEM", International Journal of Research in Marketing, Vol. 26 No. 4, pp. 332-344.

Roldán, J.L. and Sánchez-Franco, M.J. (2012), "Variance-based structural equation modeling: Guidelines for using partial least squares in information systems research", in Mora, M., Gelman, O., Steenkamp, A. and Raisinghani, M. (Eds.), Research methodologies, innovations, and philosophies in software systems engineering and information systems, IGI Global, Hershey, PA, pp. 193-221.

Sheldon, P, Rauschnabel, P.A., Antony, M.G. and Car, S. (2017) "A cross-cultural comparison of Croatian and American social network sites: exploring cultural differences in motives for Instagram use", Computers in Human Behavior, Vol. 75, pp. 643-651.

Shin, Y.H., Hancer, M. and Song, J.H. (2016), "Self-congruity and the theory of planned behavior in the prediction of local food purchase", Journal of International Food \& Agribusiness Marketing, Vol. 28 No. 4, pp. 330-345.

Sirgy, M.J. (1982), "Self-concept in consumer behavior: a critical review", Journal of Consumer Research, Vol. 9 No. 3, pp. 287-300.

Sirgy, M.J., Lee, D-J., Johaar, J. S. and Tidwell, J. (2008), "Effect of self-congruity with sponsorship on brand loyalty", Journal of Business Research, Vol. 61 No. 10, pp. 10911097.

Statista (2018a), "Most famous social network sites worldwide as of April 2017, ranked by number of active users (in millions)", available at: https://www.statista.com/statistics/272014/global-social-networks-ranked-by-number-ofusers/, (accessed 30 May 2018). 
Statista (2018b), "How big of an influence is social media on your purchase decisions?", available at: https://www.statista.com/statistics/308198/us-consumer-social-mediapurchasing-influence/ (accessed 30 May 2018).

Tsai, H-T. and Huang, H-C. (2007), "Determinants of e-repurchase intentions: an integrative model of quadruple retention drivers", Information \& Management, Vol. 44 No. 3, pp. 231239.

Wetzels, M., Odekerken-Schröder, G. and Van Oppen, C. (2009), "Using PLS path modeling for assessing hierarchical construct models: guidelines and empirical illustration", $M I S$ Quarterly, Vol. 33 No. 1, pp. 177-195.

$\mathrm{Wu}, \mathrm{C}-\mathrm{W}$. (2015). Facebook users' intentions in risk communication and food-safety issues. Journal of Business Research, Vol. 68, pp. 2242-2247.

$\mathrm{Wu}, \mathrm{J}-\mathrm{H} ., \mathrm{Wu}, \mathrm{C}-\mathrm{W}$. , Lee, C-T. and Lee, H-J. (2015), "Green purchase intentions: An exploratory study of the Taiwanese electric motorcycle market", Journal of Business Research, Vol, 68 No 4, pp. 829-833.

Xu, C., Ryan, S., Prybutok, V. and Wen, C. (2012), "It is not for fun: An examination of social network site usage", Information \& Management, Vol. 49 No. 5, pp. 210-217.

Yoo, B., Donthu, N. and Lee, S. (2000) "An examination of selected marketing mix elements and brand equity", Journal of the Academy of Marketing Science, Vol. 28 No 2, 195-211. 